\title{
The cost exemption in the freedom of information regimes of the United Kingdom and Scotland: a comparative analysis
}

\section{FIRST AUTHOR:}

\author{
Calum Liddle
}

ADDRESS: University of Strathclyde, CIS Room 1207, Livingstone Tower, 26 Richmond Street, Glasgow, G1 1XH

BIOGRAPHY: Liddle is a Researcher in the Department of Computer and Information Sciences at the University of Strathclyde. His research interests include freedom of information; data protection; and information ethics. Liddle also acts as a compliance consultant and information governance adviser to some of the country's largest public authorities.

\section{SECOND AUTHOR:}

\section{David McMenemy}

BIOGRAPHY: McMenemy is a Lecturer and Course Director for the MSc in Information and Library Studies at the University of Strathclyde. He was Editor of Library Review between 2006-2011; and the author of The Public Library (Facet, 2009) and the forthcoming work, Information Ethics: Reflection and Practice (Facet, 2015).

ADDRESS: University of Strathclyde, CIS Room 1420, Livingstone Tower, 26 Richmond Street, Glasgow, G1 1XH

ABTRACT: In this tenth anniversary year since freedom of information came into force north and south of the border, the authors, namely, Calum Liddle and David McMenemy, undertake an in-depth comparative evaluation of the parallel cost exemptions found in the Freedom of Information Act 2000 and the Freedom of Information (Scotland) Act 2002. Does Scottish FOI indeed afford a more generous disclosure entitlement? And are applicants, in turn, employing comparatively weaker rights when requesting information from analogous English and Welsh authorities? A statutory analysis of the home nation provisions is complemented by case law and a nod to contemporaneous events.

KEY WORDS: freedom of information, transparency, accountability, information governance, information management, legal research, Scotland, United Kingdom.

WORD COUNT: 5130 


\section{The cost exemption in the freedom of information regimes of the United Kingdom and Scotland: a comparative analysis}

\section{Introduction}

This year marks the tenth anniversary since both home nation freedom of information regimes came into force. The Freedom of Information Act 2000 and the Freedom of Information (Scotland) Act 2002 are certainly of the same pedigree and broadly similar with, for example, parallel conditions attached to the general entitlement; however, any broad-brush evaluation of Scottish FOI would conclude that there are advantages afforded to the applicant in contrast, at least, to those rights otherwise afforded to applicants employing the United Kingdom's counterpart regime. Both regimes provide a refusal mechanism to those scheduled public authorities subject to either Act where the estimated cost of complying with a request for information would exceed a prescribed amount. So what of the consequences to applicants: Does the freedom of information regime in Scotland, on the grounds of the prescribed cost limitations, afford a more generous disclosure entitlement? Are applicants, in turn, employing comparatively weaker rights under the UK regime when requesting information from analogous UKwide, English, Welsh and Northern Irish public authorities? And, if so, might the Scottish regime, therefore, be said to be comparatively more disclosure prone?

This article constitutes an in-depth comparative evaluation of the home nation cost exemptions, in addressing those questions posed. The authors undertook an analysis of the parallel statutory provisions using a comparative lens as a technique to render the home nation FOI regimes externally consistent; that is to say, in the simplest of terms, does the UK Act align with the Scottish Act? The reasoning is syllogistic, the arguments by way of analogy. The inquiry is complemented by case law and a nod to contemporaneous events.

With the UK Justice Secretary, namely, Michael Gove, intending to scale back FOIA $2000^{1}$ while the Scottish Government consults on widening the scope of FOISA 2002, ${ }^{2}$ shifting trajectories make this article an all-the-more timely endeavour and its findings, it is hoped, of wider interest. This paper suggests that, on evaluation of the parallel cost exemptions, the Scottish regime does, indeed, afford a more generous disclosure entitlement. However, any broad-brush statement of one regime being stronger than the other should carry caution given the distinct paucity in any research concerned with frontline day-to-day operational practice; that which might, for example, concern the ethnographic, among other considerations.

\section{Background}

Both home nation freedom of information regimes, enacted under FOIA 2000 and FOISA 2002, came into force on New Year's Day in 2005. Scotland's FOI regime provides any person who requests information from a "Scottish public authority" a right, subject to a string of technical conditions and exemptions, to be provided with the information held by that authority. The UK regime, in a similar vein, applies to the public authorities of the other home nations, namely, England, Wales and Northern Ireland and to UK-wide public authorities regardless of whether or not those authorities operate in or from Scotland. Any public authority, to which freedom of information legislation applies, is subject to only one regime. ${ }^{3}$ It is irrespective of whether the information requested relates to reserved or devolved matters. For completeness, it should be noted that a Manx Freedom of Information regime now also exists having received Royal Assent in 2015; it applies only to the Isle of Man Cabinet Office and the Department for Environment, Food and Agriculture from February 2016, and to those remaining government departments and public authorities from February 2017. Requests can be made for information created on or after 11 October $2011^{4}$ (the date the current Manx parliament was elected to the High Court of Tynwald). ${ }^{5}$ 


\section{A comparative analysis of the cost exemptions}

\section{The monetary limit}

At section 12 of FOISA 2002 a Scottish public authority need not comply with a request for information if the authority estimates that the cost of compliance will exceed the amount set out in regulation 5 of the Freedom of Information Fees for Required Disclosure (Scotland) Regulations 2004, (the 'Scottish Regulations' for brevity). Where the projected costs do not exceed $£ 100$, no fee is be payable. ${ }^{6}$ Where the estimate exceeds $£ 100$ but does not exceed $£ 600$, the fee is not to be more than 10 per cent of the difference between the projected costs and $£ 100 .^{7}$ With the option to set the chargeable amount below ten per cent the fee can be, effectively, waived. The maximum cost to the applicant, in any case, is $£ 50$ (10 per cent of (£600-£100)). In Scotland, the estimate of the cost of staff time in undertaking the prescribed tasks to comply with a request for information is capped at just $£ 15$ per hour per member of staff. ${ }^{8}$ On staff cost alone the regulations, therefore, permit a minimum of 40 hours dedicated work per request for the prescribed activities in responding to a request for information.

Under the UK FOI regime, the fees attached to the cost exemption at s 12 of FOIA 2000 are governed by the Freedom of Information and Data Protection (Appropriate Limit and Fees) Regulations 2004, (the 'UK Regulations' for brevity). There is no charge where the projected costs fall within the appropriate limit: currently $£ 600$ for central government and $£ 450$ for all other UK public authorities. ${ }^{9}$ However, the UK Fees Regulations set the staff time charged for undertaking the prescribed tasks necessary to comply with a request for information at a flat rate of $£ 25$ per hour, per member of staff. ${ }^{10}$ The UK regulations, therefore, equate to 24 hours of dedicated time per request submitted to central government or 18 hours work at any other public authority. This is 16 hours and 22 hours, respectively, less than what any Scottish public authority will dedicate to a submission under FOISA 2002. The Scottish hourly charge is not only lower but it is "capped" as opposed to being a "flat-rate". In other words, the number of hours dedicated to the prescribed tasks associated with any FOI request might indeed even exceed that of 40 hours in Scotland where, for example, a lower waged staff member were deployed.

In the Office of the Scottish Information Commissioner's Decision 211/2012, the regulator was not convinced by the Scottish Government in Edinburgh that the task, as a whole, of responding to a request for the engagements of a special adviser justified the maximum hourly rate of $£ 15$ per hour. ${ }^{11}$ In Decisions which have followed, the Scottish Government, and other public authorities, have altered the hourly rate in calculating the cost estimate. In Decision 055/2013, for example, the Government's estimate for retrieving information relating to the knighthood of Sir Brian Souter was calculated on the civil service staff grade at A3; this was said to be appropriate for the staff, in this instance, who would undertake the search on Objective ${ }^{12}$ at $£ 9.50$ per hour. ${ }^{13}$ The Scottish Commissioner must be convinced that the hourly rate is appropriate for each of those named tasks necessary to facilitate the disclosure. ${ }^{14}$ The difference between the regimes, in this respect, is pronounced: the UK applicant is limited in so far as the amount of time which will be dedicated to any response and, in turn, the amount of information disclosable in so far as that which might be accomplished within the monetary limit. The upper monetary limit of FOISA 2002, and in turn the number of hours dedicated to the facilitation of each disclosure, provides the Scottish applicant a distinct, albeit comparative, advantage.

\section{The determination}

There are limited and exhaustively prescribed tasks in both of the home nation FOI regimes which a public authority might consider as part of the calculation of the costs 
associated with any prospective disclosure. A breach of the upper-limit as a result of this calculation would, of course, justify a refusal notice. ${ }^{15}$ Scotland's general entitlement provides a single right to applicants: to be provided the information. ${ }^{16}$ The authority, therefore, is not entitled to charge for any costs incurred in determining whether it, in actual fact, holds the requested information. ${ }^{17}$ In other words the search, however timely, required to substantiate whether the information requested exists is, ultimately, free. The public authority is entitled to charge, thereafter, for the direct and indirect costs incurred in "locating, retrieving and providing information". ${ }^{18}$

The general entitlement to information is different in FOIA 2000 and lends itself to a significant departure when calculating the cost of complying with a request and, in turn, as to whether the cost exemption can be engaged by the public authority. The right to know in FOIA 2000 is established by placing two related obligations on public authorities: First, when an applicant requests information a public authority has a duty to write to the applicant saying whether it holds the information. ${ }^{19}$ This is known as the duty to confirm or deny. And second, if the authority does hold the information it must communicate it to the applicant. ${ }^{20}$ It follows then that the UK Regulations permit for the charging of the determination as well as costs associated with locating the information; retrieving the information; and extracting the information. ${ }^{21}$ The initial search, contrary to FOISA 2002, is chargeable. If it will take over 24 hours for a central government department or body, or 18 hours for any other public authority, to determine whether the information is held, then there will be no statutory requirement to disclose the information requested under FOIA 2000; the cost exemption is engaged where the staff time required by any authority to make a 'held/not held' determination exceeds the prescribed amount. And the initial search will, in any case, contribute to the comparatively short amount of time afforded by the UK regime in undertaking the other prescribed tasks necessary to facilitate a disclosure. Conversely, public authorities in the UK with poor recordkeeping functions may be escaping FOI obligations if, say, practitioners are unable to search appropriately for requested information.

Both home nation regimes do, however, prohibit their scheduled public authorities from charging for any costs incurred in deciding whether the information should or should not be disclosed. In other words, practitioners cannot charge for the time taken to consider any potential exemptions which might justify a refusal notice to the applicant. This extends itself to a practitioner's time calculating a cost estimate for the purposes of $\mathrm{s}$. 12(1) of FOISA 2002 and s. 12(1) of FOIA 2000.

\section{Redaction}

The home nation FOI regimes have a special relationship with the Data Protection Act 1998 (the 'DPA 1998'). The majority of FOI submissions to public authorities are likely to include, bearing in mind the wide-scoping definition of "personal data" provided at s. $1(1)$ of the DPA 1998, incidental requests for third party personal data. A public authority will need to consider whether the information, either by itself or in combination with other information, actually constitutes personal data and, in turn, whether disclosure of third party personal data to the world under FOI would be compliant with the DPA $1998 .^{22}$ Neither regime affords such a task, however time consuming, to form any part of the calculation of costs. But the exemption can, in instances, be avoided and a disclosure therefore permitted by way of redacting, or 'blacking out', that information which would otherwise engage the exemption. The process can involve subtleties and prove to be a time-consuming affair. The process of redaction, while of course in the main used for the purposes of blacking out third party personal data, is not restricted to the parallel home nation exemptions for such data. Indeed, redaction has been employed, for example, by the Ministry of Defence to facilitate disclosures which would otherwise engage the exemption concerned with national security and international relations $^{23}$ and local authorities, too, often use redaction to make a disclosure of 
information which would, or would be likely to, otherwise prejudice or prejudice substantially the effective conduct of public affairs. ${ }^{24}$

The Scottish Information Commissioner has determined that public authorities can charge for the costs incurred in redacting a document under the FOISA 2002 regime. The charge is qualified: costs are restricted to those which involve the physical process of redaction alone. In other words, an authority is not allowed to charge for the reading and selection of material necessary as part of such a determination. The charge is limited to the "purely administrative task". ${ }^{25}$ The charge covers the very end process alone, for example, of "deleting sections from an electronic record or using a black marker pen to redact information from a physical record (and then, where necessary, copying the redacted version to ensure that no redacted information can be read)" ${ }^{26}$ The UK Information Commissioner's guidance, in alignment with the Scots, states that the costs associated with redaction which might be included as part of any cost calculation extend merely to "tape or black ink or the use of specialist equipment (for example, rental or licensing [of redaction software]) for the specific activity of redaction". ${ }^{27}$

There is a further qualification in the Scottish regime on redaction: costs can only be included in so far as those which relate to the requested information and not that information which is otherwise present but falls outside the scope of the request. ${ }^{28}$ Information falling outside the scope of the request but, say, embedded within a document sought, might be described as being incidental. The Scottish regime is, to this extent, in agreement with the UK in the High Court interpretation found in The Chief Constable of South Yorkshire Police $v$ The Information Commissioner [2011] EWHC 44 (Admin). That case determined that costs permitted for "extracting the information from a document containing it" in the UK Regulations ${ }^{29}$ relates only to that information which has been requested:

$[T]$ he words "extracting the information from a document containing it" $[\ldots]$ can only refer to extracting the information which has been requested from a document which contains the information which has been requested, thereby distinguishing it from the information in the document which has not been requested. ${ }^{30}$

If the Scottish Commissioner is satisfied that the cost of providing information to a requester exceeds $£ 600$, then the public authority will not be ordered to disclose the information. Redaction costs, therefore, may very well contribute to a lawful refusal by a Scottish public authority. The Commissioner is likely, however, to instruct the public authority (in line with its duty to provide reasonable advice and assistance) to consult the requester to find out whether it is possible to narrow down the scope of the information request in order to bring it within the $£ 600$ limit, if the authority has not already done so. ${ }^{31}$ Therefore, the applicant might, simply, provide an explicit indication that they do not wish to receive that information which is considered exempt thereby removing any costs associated with redaction from the public authority's cost calculation. ${ }^{32}$ There is no pronounced difference between the home nation regimes on the calculation of any redaction costs.

\section{Aggregation}

There are, however, significant differences concerning the rules of aggregation relevant to a public authority's calculation of costs for the purposes of the exemption. In Scotland, multiple requests contained in the same piece of correspondence, from the same applicant, are read as self-standing submissions, as opposed to constituent parts of the same request. In Scottish Decision 055/2013 the applicant submitted ten separate letters to the Scottish Ministers requesting information regarding the knighthood awarded to Sir Brian Souter and the Ministers' involvement in the honours system. Those 
ten letters contained 35 separate information requests. Each request constitutes a different request for the purposes of FOISA 2002 and, as such, each of the 35 requests assumed its own cost limit.

Similarly, in Decision 161/2012 where the applicant asked the Scottish Prison Service for information relating to the procurement of a laptop facility and any correspondence relating to the implementation of a policy for prisoner access to such a facility, this required the need for two distinct cost estimates to be undertaken by the authority. Aggregation of any one person's requests is not systematic; indeed, it is quite to the contrary:

In a small number of cases, the Commissioner has found that multiple requests made in the same letter or email are so interconnected that the requests should be treated as one for the purpose of determining whether the cost of complying with the request exceeds $£ 600$. $^{33}$

It is in these "small number" in which requests, in practice, are ever aggregated. In Scottish Decision 134/2012, the Commissioner was satisfied that the applicant's six requests, for minutes of meetings held by the Scottish Criminal Cases Review Commission, could be considered as one because separating the information required to address and calculate the six requests was a contrived affair. The SIC said:

Essentially, on any reasonable interpretation, the information requested is such that the identification and location of what is required to address each point cannot realistically be separated out into discrete tasks $[\ldots] .^{34}$

Aggregation is, however, systematic at the coal face of the UK FOI regime due to lax rules governing the practice. At section 12(4) of FOIA 2000 a public authority can aggregate the cost of complying with two or more requests subject to the conditions at regulation 5 of the UK Fees Regulations: providing the requests come from the same individual within a 60 working day period and concern similar information. In UK Decision FS50503796, the applicant's requests for information held by the Commissioner of the Metropolitan Police Service - which concerned surveillance operations - were aggregated and upheld as exempt at section 12 of FOIA 2000 by the IC on appeal. What seems troubling, in this case and others, is the test for lawful aggregation. The requests, in FS50503796, sought information regarding the number of surveillance operations undertaken, details relating to staff commitment and the number of persons under surveillance. The information requested was not held as an aggregate record. Nor was the information indistinguishable from one request to the next, as the Scottish regime would have understood.

The UK test for aggregation merely depends upon a test of "similarity, to any extent". ${ }^{35}$ It is based on mere thematic judgment making aggregation of any one person's requests a systematic procedure. Aggregation in Scotland, to the contrary, depends upon whether separating the information required to address and calculate the interconnected would be "a wholly artificial exercise". ${ }^{36}$ The test for aggregation is wholly inconsistent between the home nation regimes. The UK rules concerning aggregation, which have evolved through the UK regulatory Decision Notices and official guidance, in comparative terms presents an impediment to the rights of applicants under FOIA 2000 and the amount of information disclosable in response to the requester within the cost limit.

\section{Supplementary charges}

The Scottish Regulations permit the charging for providing the information and this extends itself to, for example, the cost of printing and posting tangible copies of the 
disclosure. ${ }^{37}$ Likewise, the UK Regulations provides that a public authority can charge for the costs it reasonably expects to incur in communicating the disclosure to the requestor. ${ }^{38}$ This too would extend itself to, for example, printing or photocopying, postage and other forms of transmitting the information.

FOISA 2002, contrary to FOIA 2000, provides an explicit provision to disabled applicants where they might wish to express a preference for receiving information. ${ }^{39}$ However, the limits of the duty at section 11(1) of FOIA 2000 - where an applicant may request the information disclosure in "another form acceptable" - should not prevent public authorities from any duty to make special arrangements in light of the Equality Act $2010 .{ }^{40}$ Neither of the home nation regimes, therefore, can ever lawfully issue a fees notice to seek payment for the provision of information in large font or braille, for example. Other statutory obligations too could not be charged for, such as any translation obligations under the Welsh Language Act 1993 attached to public authorities in Wales falling under the scope of FOIA 2000. The home nation regimes, to this extent, are in tandem.

\section{The fees notice}

Where a public authority under either regime wishes to make a charge for providing information it must give the requester a fees notice within 20 working days after the date of receipt of the information request, setting out the projected costs of dealing with the request. ${ }^{41}$ The public authority need not comply with the general entitlement until the fees notice has been paid; the applicant must pay the notice within three months beginning with the day in which the notice is given for the request to remain valid. ${ }^{42}$ The calculation is based upon those tasks associated under either regime which are prescribed in the Regulations. ${ }^{43}$ The projected costs should be a reasonable estimate of the costs likely to be incurred - and based only on the estimated actual costs to the public authority. Dunion describes a fees notice as constituting "a quote". ${ }^{44}$ But it cannot be reneged on following payment by the applicant. Guidance from the current Information Commissioner in Scotland states:

Where a fees notice is paid, and the public authority finds out later that it underestimated the costs of dealing with the request, the authority cannot ask the requester to pay the additional cost. It is the public authority's responsibility to ensure that the fees notice contains an accurate estimate of what the work is likely to cost [OSIC emphasis]. ${ }^{45}$

Coppel confirms that the OSIC guidance is in accordance with that of the UK freedom of information regime: the public authority must bear the burden of any costs, where necessary, should the actual costs exceed, in practice, the quote provided in the fees notice. ${ }^{46}$

Further to the explicit application by a public authority, north or south of the border, of the cost exemption to withhold information when the calculable costs exceed the prescribed limit, a fees notice might be issued in any case in order for a disclosure to be made. The practicality is limited. Under the UK regime, where it would not exceed the appropriate limit to comply with a request a public authority may still charge a fee to cover actual costs it reasonably expects to incur in determining whether the information requested is held. This fee relates to the first of the two related obligations attached to the general entitlement under FOIA 2000. In other words, a fees notice can be issued in order for the public authority to, in turn, determine whether the requested information is indeed held - even if the information will not be provided. ${ }^{47}$ Furthermore, regulation $6(2)$ of the UK Regulations goes on to provide that a public authority can charge for the costs it reasonably expects to incur in communicating that determination to the requestor. "This generally means that a public authority can only charge for expenses actually 
incurred, for example, photocopying or postage," the ICO claims. The costs would be limited to those expenses actually incurred as, bear in mind, public authorities are not permitted to charge for the staff time in carrying out the communication activities. ${ }^{48}$

Under the Scottish regime a public authority may of course, seek payment to cover up to 10 per cent of costs where the estimate to comply exceeds $£ 100$ but does not exceed $£ 600$. And so a fees notice, in this case, could be issued. Scottish public authorities are explicitly forbidden, contrary to the UK regime, in accounting for the costs incurred in determining whether the authority holds the information specified in the request. ${ }^{49}$ Furthermore, no fees notice is to be issued where information is exempt from disclosure. The authority must satisfy itself that information can be disclosed before issuing a fees notice. ${ }^{50}$ But the Scottish regime does, however, in line with its UK counterpart regime, allow public authorities to charge for the actual cost of postage, packaging and the likes, in any case. ${ }^{51}$

Finally, under both of the home nation freedom of information regimes a public authority may issue a fees notice where the cost of complying with a request would exceed the upper limit but where, nevertheless, the authority still wishes to comply. The charge is calculated in accordance with the respective Regulations, attached to either of the home nation Acts, in pursuance of the prescribed tasks detailed earlier. ${ }^{52}$ But any public authority scheduled for the purposes of FOIA 2000 or FOISA 2002 can, should it choose to do so, volunteer a disclosure of information even if the circumstance is such that to do so would, in actual fact, engage the cost exemption. No charge need necessarily be sought.

\section{Conclusion}

Any broad-brush evaluation of Scottish freedom of information would conclude that there are advantages afforded to the applicant in contrast, at least, to those rights afforded to applicants employing the United Kingdom's counterpart regime. It would appear that the cost limitation, in all the circumstances, fits into this assumption. The UK cost limit is certainly, on the evidence presented here, disadvantageous to an applicant's request, comparatively at least. The hourly monetary rate, the charging of the held/not held determination and systematic aggregation make for far weaker rights afforded to the applicant employing the UK FOI regime.

Joe Fitzpatrick MSP, Minister for Parliamentary Business, claims that Scottish FOI is "more disclosure prone" than the UK regime. ${ }^{53}$ It is an assertion which the United Kingdom Information Commissioner, namely, Christopher Graham, while admiring many advantages of the Scottish FOI regime, remains sceptical. ${ }^{54}$ On the balance of the cost exemption attached to each of the home nation Acts it seems, however, reasonable, at least, to assume that Scottish FOI is indeed more disclosure prone: first, the quantity of information disclosable is greater in Scotland within the staff time afforded by the monetary limit, certainly. And, second, it might be suggested that the cost exemption in Scotland is one which would be engaged far less bearing in mind the limited prescribed tasks used for calculating costs. In other words the upper limit can be avoided. In turn disclosure success rates might be higher in Scotland under FOISA 2002 than those which are accomplished by analogous UK public authorities under FOIA 2000. Should indeed changes otherwise be made to the way the cost of retrieving information is calculated under the UK FOI regime - to allow for a practitioner's "thinking time" 55 or to allow for the charging of the time taken for redaction ${ }^{56}$ - it would only move to widen its trajectory from Scotland.

However, any broad-brush statement of one regime being stronger than the other should carry caution, and a heavy disclaimer, given the distinct paucity in any quantitative comparative compliance data with regards to disclosure rates. And, 
furthermore, there is little, if any, substantial academic insight concerned with comparative frontline and real-world operational practice, that which might, for example, concern the ethnographic. Nor did our doctrinal evaluation here, for example, concern itself with comparative record keeping practices - for better or worse. ${ }^{57}$ Any public authority might, bear in mind, should it choose to do so, volunteer a disclosure of information even if the circumstance is such that to do so would, in actual fact, engage the cost exemption. No exemption may necessarily be relied on. No charge need necessarily be sought.

\section{END}




\section{References}

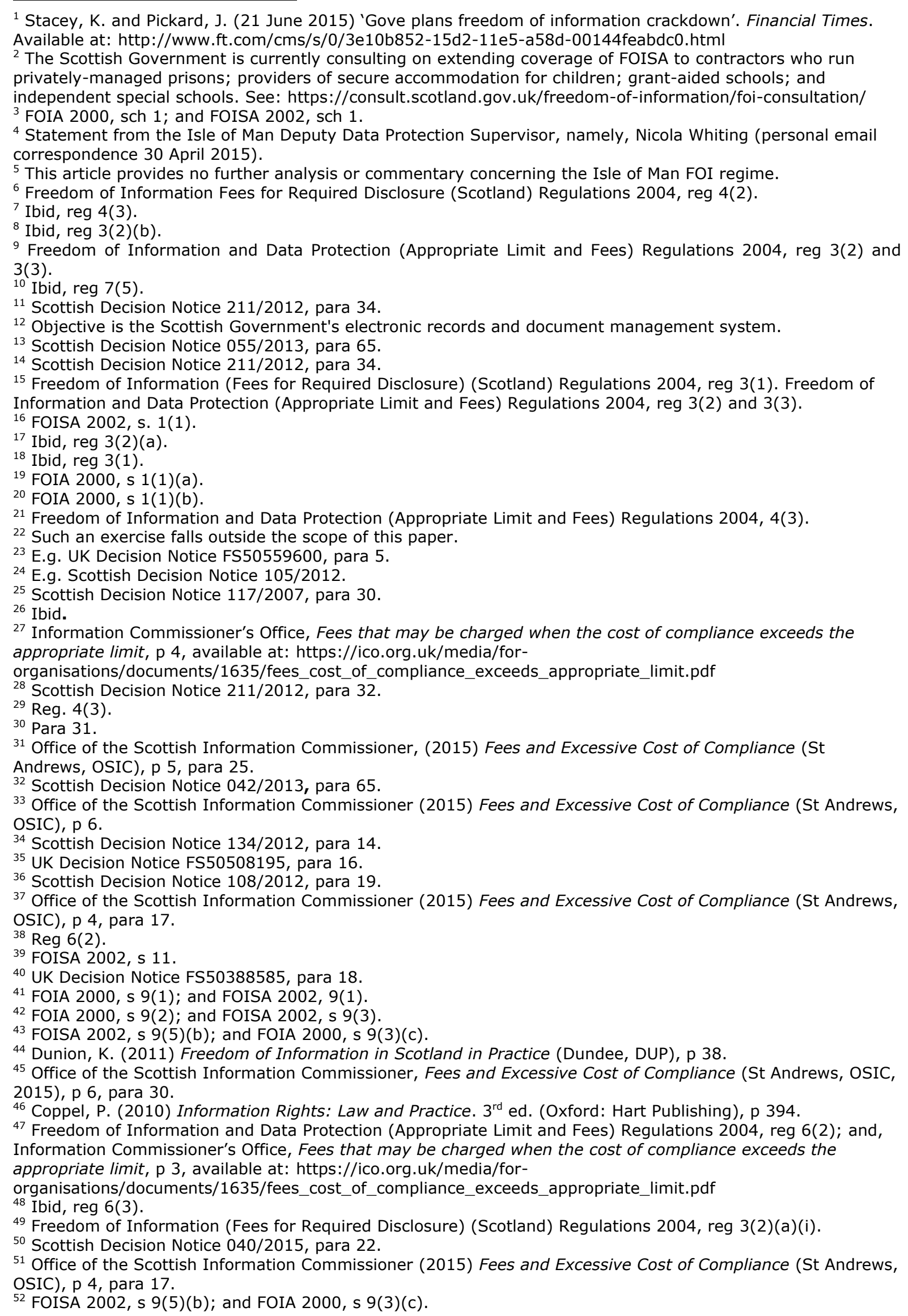


${ }^{53}$ Fitzpatrick, J. 'The Scottish Government Address'. Holyrood Conferences: 'Freedom of Information: 10 Years of FOISA', Dynamic Earth, Edinburgh, 11 December 2014. See: http://foi.holyrood.com/

${ }^{54} \mathrm{Graham}, \mathrm{C}$. 'Address form the UK Information Commissioner'. Holyrood Conferences: 'Freedom of

Information: 10 Years of FOISA', Dynamic Earth, Edinburgh, 11 December 2014. See:

https://ico.org.uk/about-the-ico/news-and-events/news-and-blogs/2014/12/christopher-graham-speaksabout-foi-and-scotland/

${ }^{55}$ Stacey, K. and Pickard, J. (21 June 2015) 'Gove plans freedom of information crackdown'. Financial Times.

Available at: http://www.ft.com/cms/s/0/3e10b852-15d2-11e5-a58d-00144feabdc0.html

${ }^{56}$ Ministry of Justice (2012) Government Response to the Justice Committee's Report: Post-legislative Scrutiny of the Freedom of Information Act 2000 (London, The Stationary Office), p 9, para 14.

${ }^{57}$ E.g. Pickard, J. and Stacey, K. (16 June 2015) 'Freedom of information is Mission Impossible for Downing St emails'. Financial Times. Available at: http://www.ft.com/cms/s/0/d42d3c68-141d-11e5-abda-

00144feabdc0.html?siteedition =uk\#axzz3dKTIPOkg 